\title{
TEACHERS PERSPECTIVE IN NEW LEARNING MODALITIES VIS-A-VIS STUDENTS ABILITY: PHENOMENOLOGICAL INQUIRY
}

\author{
Angelica Kean Bantasan ${ }^{1}$, Ma. Melanie N. Edig $^{2}$, Ronald S. Decano ${ }^{3}$ \\ ${ }^{1}$ Graduate Student, Doctor of Philosophy in Educational Management, Davao del Norte State College \\ ${ }^{2}$ Faculty, Institute of Advanced Studies, Davao del Norte State College \\ ${ }^{3}$ Dean, Institute of Advanced Studies, Davao del Norte State College
}

Article DOI: https://doi.org/10.36713/epra9375

DOI No: 10.36713/epra9375

\begin{abstract}
As far as I observed, teachers are now being held to new levels of accountability for improving student outcomes. It sought the personal hands-on experiences of participants and its perspective towards attaining quality education in new normal modalities. The research design of this study utilized the phenomenological method to determine the teacher's perspective on the learning modalities vis-a-vis students' ability in The Rizal Memorial Colleges, Inc. The participants of this study were composed of 10 Senior High School teachers. The data obtained identified emergent themes clustered, namely: appropriateness of learning modalities, interactions in transmitting knowledge effectively, communication and connection, encouraging learners, helping learners, engaging different learning modalities, developing learning competency, achieving different teaching approaches, considering student's needs, proposing new learning system, and organizing appropriates activities. Therefore, the results promote a new paradigm for delivering education and call for a new explicit structure of support for professionals in new normal learning system of education. With this, the implications to the teachers were to provide improvement, self-esteem, and self-empowerment, to do better for the best result for the academic performance of the students which serve as a reference for the school heads in giving school intervention activities.

KEYWORDS: Teachers Perspective, New Learning modalities, and students' ability
\end{abstract}

\section{INTRODUCTION}

A phenomenological investigation of teacher perspectives on new learning modalities and students' abilities is our greatest knowledge of the present research. The methods for enticing students are changing at an everincreasing pace. These criteria call new explicit support structures for professionals in a new normal learning system, which encourage a new paradigm for providing education. Criticism of teachers who don't think students can attain their full potential is a sign that they aren't critical enough. Respect is shown to students as unique people with unique personal and familial histories and a wide range of abilities, opinions, skills, and interests.

It is a profession that requires the ability to be responsive to new demands and changing needs. In recent years, school reform promoting high-stakes testing in the name of improving academic achievement has dominated the list of problems demanding consideration. Merely informed of the results of decisions made, teachers might not clearly understand why or how those decisions are made (Feir, 2019).

The University of Texas at Austin's worldwide context. Teaching must be rethought in light of the new standards, as well as the important themes that run through them if we are to enhance student outcomes in our new educational system. Diverse Learners Benefit from Personalized Learning. Teachers must have the information, resources, and abilities necessary to cater instruction to the widest possible range of student variations due to the 
rapid growth in student diversity. Teachers must understand that all students contribute a variety of advantages to their learning, including diverse backgrounds, skills, talents, and previous knowledge, as well as their native language, culture, and values from their families and communities (Feir, 2019).

In the Philippine context, Reyes (2018) noted that teachers monitoring tools for learners take a vital role. Teacher's personality in the learning place is a mirror or factors of student's performance vis-a-vis on how teacher being teachers then the sense of belongingness is prevalent in every learner, thus, every student does learn with joy and contributing to the achievement of the academic outcomes.

In the local context, According to Grunig (2017). Cagayan Province teacher comfortable and knowledgeable personality in teaching is standard strategy and sequential legs of the journey in education must arise from a teaching learning process, which explains why a learner is in be stimulated. Every activity in the school should seek to fill this purpose, the mission thus guiding all strategic decisions. A school vision describes what the school may have achieved in fulfilling its mission. From the vision follows the long-term goals of a standard strategy.

Mikkelsen (2017) averred that student's ability and behavior can take many different actions to improve bottom line outcomes such as enhancing process efficiency, upgrading equipment or developing new era of education However, research that the recent teacher perspective of new learning modalities vis-a-vis students' ability can have an impact on students' performance.

\section{Research Design}

\section{METHODOLOGY}

A qualitative research, phenomenological approach was selected as the research approach for this study to focus on the commonality of a lived experience within a particular group or individual. The approach's fundamental goal based on (Creswell, 2013) is to arrive at a description of the nature of the particular phenomenon. The researcher would like to determine the teachers perspective in new learning modalities vis-a-vis students ability of The Rizal Memorial Colleges, Inc.

\section{Research Locale and Sampling}

The participants of this study were chosen via Purposive sampling technique. This sampling method requires researchers to have prior knowledge about the purpose of their studies to properly choose and approach eligible participants. Ten (10) teachers who met the criterion were selected. These criteria plays the vital role in choosing the right participants for the study, for it gives bases on how reliable and credible. This study was conducted in a private school at Davao City, The Rizal Memorial Colleges, Inc. The school is strategically located at RMC Buildings, Purok 5, Lopez Jaena\& F. Torres Streets, Barangay 8-A Poblacion District, Davao City.

\section{Data Collection Procedure}

Thematic Content Analysis was used in interpreting the responses made by the key participants in determining the presence and experiences of the Senior High School on teacher's perspective in new learning modalities vis-a-vis students ability: phenomenological inquiry. Their responses were processed and conducted through analysis. Transcripts were coded in considerable detailed with the focus shifting back and forth from the key claims of the participants to the researcher's interpretation of the meaning of the responses and subjectively interpreted. Meanwhile, the notes that will be obtained from in-depth interview will transcribed immediately. The researcher will be looking for common themes that will be found among the responses to each question. In this phase, the researcher will use the thematic analysis in analysing the gathered data.

\section{RESULTS AND DISCUSSION}

This section presents the results of the data gathered from the In-depth Interview with the participants. It aims to interpret all the data, to analyze logically, and discuss what are the things discovered and compare the result to the existing studies related in this research.

The data obtained identified emergent themes clustered, namely: appropriateness of learning modalities, interactions in transmitting knowledge effectively, communication and connection, encouraging learners, helping learners, engaging different learning modalities, developing learning competency, achieving different teaching approach, considering student's needs, proposing new learning system, and organizing appropriates activities. 
This means that the teachers has guide to provides a planning tool that emphasizes the importance of family, school, and community partnerships. Specifically, the guide suggests that student's ability and school goal can maintain and continue quality learning despite of quick change of system of education a list of key community partners to connect families, communicate with these stakeholders about plans, and identify how do the new learning modality implemented and can deploy their resources to help with the learners and recovery to create a more integrated support system for students ability in the middle of quick change and embrace the new learning modality of the Rizal Memorial Colleges.

\section{Implications for Future Direction}

Blended learning strategies rely on a combination of technologies, print materials, and asynchronous and modular learning modes. The RMC Administration has responded by developing learning plans that incorporate BLENDED learning strategies, which combine technologies and print materials as well as synchronous and nonsynchronous modes. Since many instructors are struggling to adapt to these new ways of delivery, it is understandable. Sometimes teachers have to swiftly modify the course material they created for a physical classroom to an online or remote version.

Based on the objective of this study is to discover the teacher's perspective on the learning modalities vis-avis students' ability. It sought the personal hands-on experiences of teachers participants' ability and its impact towards attaining quality education. Participants' responses were grouped into themes such as: appropriateness of learning modalities, interactions in transmitting knowledge effectively, and communication and connection.

Appropriateness of learning modalities undoubtedly poses certain challenges, not least of all the question of how to communicate clearly to students on how they may be expected to interact with your new course materials and/or new modes of communication in the teaching-learning process. Some aspects may remain unchanged; however, others may have to adjust to accommodate the new ways in which students may be interacting with you, the course materials, and each other.

As I analyzed from the responses of teacher's participant's inappropriateness of learning modalities, however, to combine these new instructional mediums into the teaching-learning process, it is crucial to be attentive to how communicate students. Students may also be new to the online platform's/modalities were using, and given the unusual circumstances, they may be dealing with situations outside of virtual classroom that may affect their ability to engage with teaching learning process.

This should point to ways teachers can become content curators, and provide recommendations so that they do not overwhelm pupils with excessive lectures, lessons plan, and homework. Every teacher has her /his teaching style, and traditional teaching styles evolve with the advent of differentiated instruction. More teachers are adjusting their approach depending on their students' learning needs and quick changes demands on time.

As the researcher considered the student's needs, the teaching styles evolved. Still, the teachers asked questions, and frequently ask themselves, as they embark on their careers, and occasionally pause along the way to reflect on their perspective based on their observations, experiences, and insight to understand the differences in teaching in new learning modalities, it's helpful to know where the modern concept of classifying teaching methods originated considering students' needs or vis-à-vis student ability.

\section{Future Directions}

RMC ADMIN. The administrators of The Rizal Memorial Colleges, Inc. You should conduct a study about the imparted resources included access to technology and devices for students, teacher training in remote instruction, strategies for motivating students, ways to address the loss of students' hands-on learning opportunities, and strategies to support students' social and emotional learning considering the findings of this study about learning modalities vis-a-vis students ability on teachers perspective from the responses and merged the themes is now cleared and highlighted for all the concerns of school stakeholder.

PRINCIPAL. The principal of the Integrated Basic Education Department (IBED) of RMC valued the results of this study as a reference for the school heads in the giving school intervention activity to help the students coped their learning difficulties in the new normal learning system and help teachers subordinate recovered and sustained the good attitude towards the teaching-learning process in new learning modalities 
TEACHERS. The teachers of the Integrated Basic Education Depart of RMC should provide levels of accountability for improvement of learner's outcomes. These standards embrace these new Learning modalities, emphasizing and describing effective teaching pedagogy based on teachers' perspective that leads to improved student achievement.

FUTURE RESEARCHERS. You must conduct a study on the different considerations and teachers perspective in new learning modalities vis-a-vis student's ability, this study would serve only as reference for future researchers as they conduct similar or comparative study.

\section{ACKNOWLEDGEMENT}

I, Angelica Kean A. Bantasan, would like to extend my heartfelt appreciation and gratitude to the following people who contributed immeasurably to the success of this piece of work. Dr. Ronald Decano, research adviser and the Dean of the Graduate School of Davao del Norte State College for his encouragement to finish this research. The examiners panel shares their constructive comments and suggestions that helped me improve this manuscript well. To Dr. Mark Van M. Buladaco, who was helping and finishing this paper for publication. In addition, I would also like to thank my parents and friends for being my inspiration and to their support. To my teachers respondents who contributed greatly to make this manuscript possible within a limited time frame. Finally, and most importantly, I would like to thank to our almighty God for the guidance and power 1 to achieve this great goal

\section{REFERENCES}

1. Brown JL, Jones SM, and LaRusso MD, (2018). Improving classroom quality: Teacher influences and experimental impacts of the 4Rs Program. Retrieved from Journal of Educational Psychology. 2010; 102:153-167.

2. Burchinal M, and Barbarin O. (2017) Predicting child outcomes at the end of kindergarten from the quality of prekindergarten teacher-child interactions and instruction. Retrieved from Applied Developmental Science. 2008; 12:140153.

3. Cameron CE, Connor CM, and Morrison FJ. (2017) Effects of variation in teacher organization on classroom functioning. Retrieved from Journal of School Psychology. 2005; 43:61-85.

4. Creswell, J.W. (2013). Qualitative Inquiry \& Research Design: Choosing Among the Five Approaches. Thousand Oaks, CA: SAGE Publications, Inc. (pp. 77-83)

5. Emmer ET, Stough LM. (2017). Classroom management: A critical part of educational psychology, with implications for teacher education. Retrieved from Educational Psychologist. 2001; 36:103-112.

6. Gage NL, Needels MC., (2017) Process-product research on teaching: A review of criticisms. Retrieved from The Elementary School Journal. 1989; 89:253-300.

7. Greenwood CR, Carta JJ, Dawson H. (2017). Eco behavioral Assessment Systems Software (EBASS): A system for observation in education settings. In: Thompson T, Felce D, Symons FJ, editors. Behavioral observation: Technology and applications in developmental disabilities. Retrieved from Baltimore, MD: Paul H. Brookes; 2000. pp. 229-251.

8. Greenwood CR, Carta JJ, Kamps D, Terry B. (2018). Development and validation of standard classroom observation systems for school practitioners: Eco behavioral Assessment Systems Software (EBASS) Exceptional Children. 1994; 61:197-210.

9. Maxwell, J.A. (2013). Qualitative Research Design: An Interactive Approach. Thousand Oaks, CA: SAGE Publications, Inc. (pp. 135-136)

10. Pianta R, Howes C., (2016). Features of pre-kindergarten programs, classrooms, and teachers: Do they predict observed classroom quality and child-teacher interactions? Retrieved from Applied Developmental Science. 2005; 9:144-159.

11. Pianta RC. (2019). Enhancing relationships between children and teachers. Washington, DC: Retrieved from American Psychological Association; 1999.

12. Roeser RW, Eccles JS, Sameroff AJ. (2018). Academic and emotional functioning in early adolescence: Longitudinal relations, patterns, and prediction by experience in middle school. Retrieved from Development \& Psychopathology. 1998; 10:321-352. 